\title{
About Non-Contact ECG Recording Devices
}

\author{
VL Kodkin* and AS Khafizova \\ South Ural State University, FSAEIHE SUSU (NRU), Chelyabinsk, Russian Federation, Russia
}

*Corresponding author: VL Kodkin, South Ural State University, FSAEIHE SUSU (NRU), Chelyabinsk, Russian Federation, Russia

\begin{tabular}{|c|c|}
\hline ARTICLE INFO & ABSTRACT \\
\hline Received: 幽 January 02, 2019 & Citation: VL Kodkin, AS Khafizova. About Non-Contact ECG Recording Devices. Biomed J \\
\hline Published: 㓞January 08, 2020 & Sci \& Tech Res 24(3)-2020. BJSTR. MS.ID.004047. \\
\hline
\end{tabular}

\section{Introduction}

Modern electrocardiography research admits that periodic ECG recording (once a half year) is not effective for early diagnosing coronary artery disease, a heart attack, and sudden cardiac death. Therefore, in recent years, more attention is paid to non-contact ECG recording.

\section{Problem and Discussion}

Several years ago, American journals published information about non-contact ECG recording with capacitive ECG sensors based on EPIC technology. There is an interesting project at the Ford company for creating an ECG recording system for drivers. Therefore, information about EPIC sensors is controversial, and several sources describe the problems faced by this technology in electrocardiography. A new startup for non-contact ECG recording from Detroit does not use a capacitive sensor and records an electrical signal by means of an antenna.

\section{Own Research Results}

The experiments conducted by the authors of this article demonstrated the possibility of ECG recording without direct skin contact and capacitive ECG sensors. The experiments conducted in 2018 proved a spatial distribution of ECG signal at a distance of 2-3 mm from the patient's body, including distribution through clothing and isolation (paper). This pointed at a wave-like character of ECG signal being a variable signal, which spreads at a distance of 3-4 mm from the patients' body. This revelation became a basis for developing new electrodes, which improve ECG recording by solving the problem of myograms and increasing ECG recording accuracy. For ECG recording, we use measuring electrodes from currentconducting fabric put on the base made of the shape memory material. This base is of a convex form on the side of the currentconducting fabric. Such a construction provides a larger contact area between the electrodes and the human body, which allows recording ECG without myograms typical for the contact between the electrode and the human body. The absence of myograms improves the quality of the ECG recording. The electrodes made of current-conducting fabric were inserted into clothing (ECG T-shirts), armchairs, and special belts. During experiments, we recorded ECG from the back and chest through one and two layers of clothing. In all cases, the signals possess the same form and time intervals. The experiments conducted with ECG T-shirt with five electrodes showed outstanding results. We invited a weightlifter to perform different exercises while wearing this T-shirt. Some of these exercises resulted in R-wave changes but did not provoke serious ECG baseline wandering. It should be noticed that, during these experiments, ECG recorder did not have any significant baseline filters used in Holter-type systems. (ECG diagrams are in Figure 1,2,3) The preprint [1], published earlier, gives more detailed results of experiments with athletes whose electrocardiograms were recorded directly during the performance of complex physical exercises. Research is ongoing. In the near future, comparative tests of ECG T-shirts and Holter monitors will be conducted, which should confirm the prospects of textile electrodes on a soft base. 


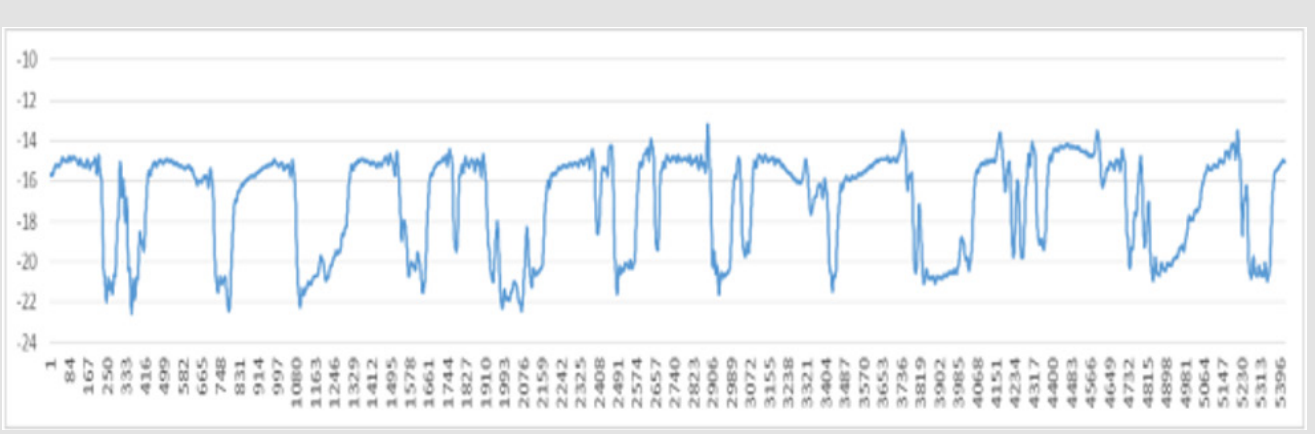

Figure 1.

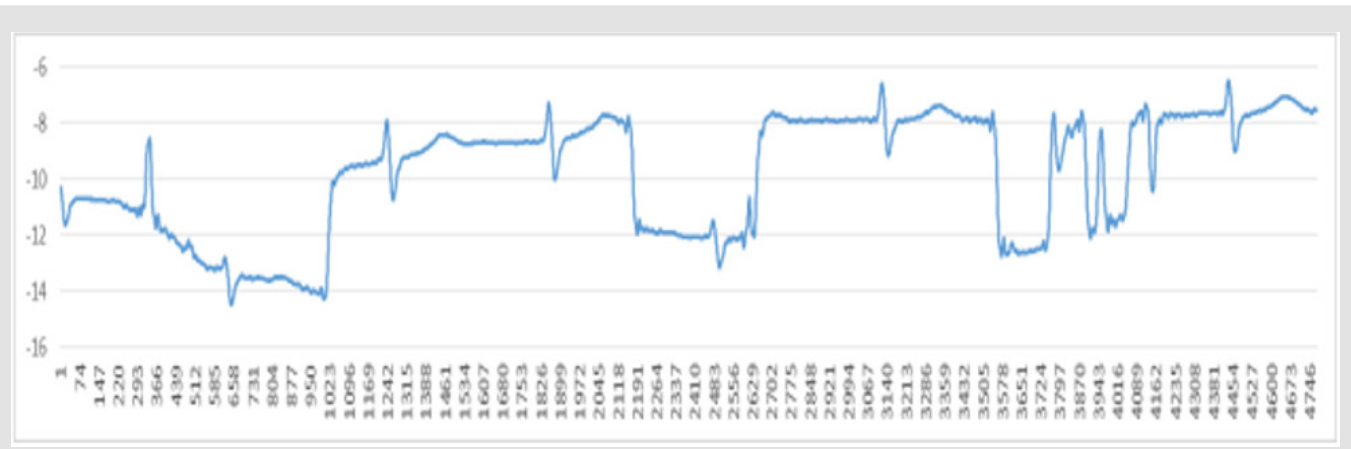

Figure 2.

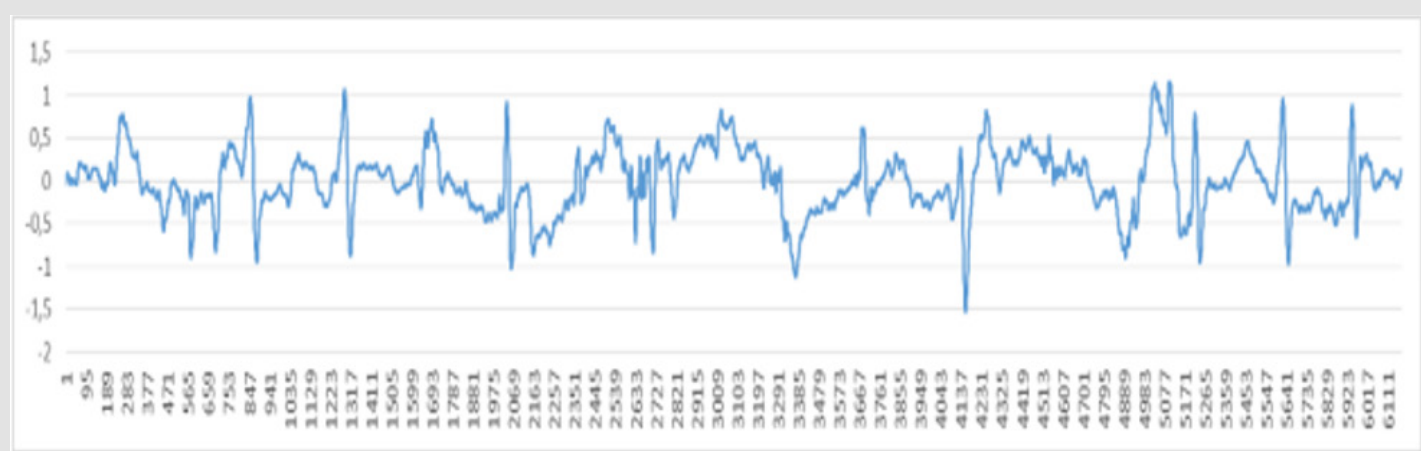

Figure 3.

\section{Conclusion}

Therefore, the recording of ECG as an electrical wave seems to have a bright future for both the non-contact ECG recording and when a reliable contact is needed for continuous ECG monitoring. The abovementioned US startup for a non-contact ECG recorder based on the principle of ECG-wave trapping emphasizes the consistency of the proposed provisions. New studies in this field

ISSN: 2574-1241

DOI: $10.26717 /$ BJSTR.2020.24.004047

VL Kodkin. Biomed J Sci \& Tech Res

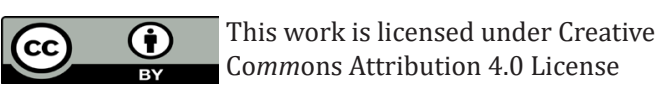

Submission Link: https://biomedres.us/submit-manuscript.php prove its relevance, importance, and potential. The company's website contains only information about team members and no data regarding the results, practical issues, stability, or accuracy. Thus, this problem is far from being solved but very important.

\section{References}

1. (2019) Continuous ECG monitoring without special electrodes and wires. Experiments with athletes.

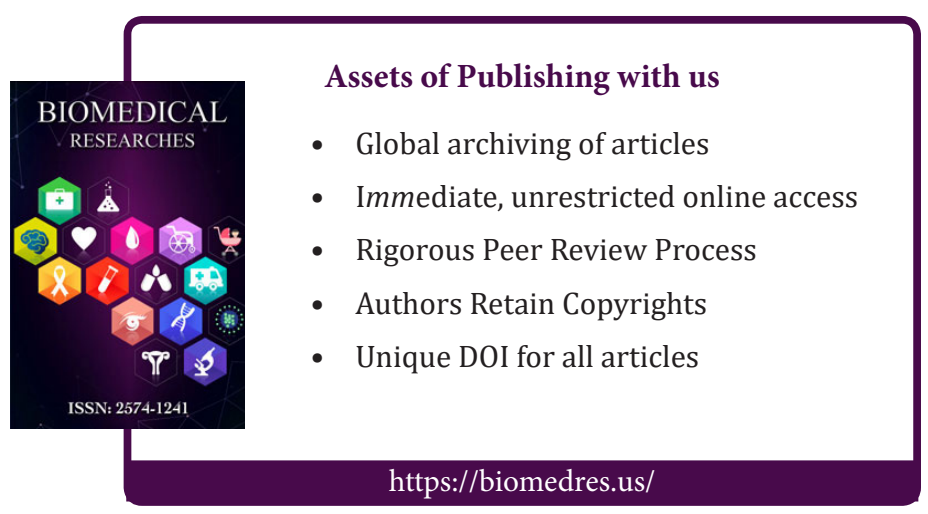

